\title{
Distamycin-stabilized Antiparallel-Parallel Combination (APC) DNA
}

Anna K. Shchyolkina, Lyudmila E. Minchenkova, Elvira E. Minyat, Yelena B. Khomyakova, Valery I. Ivanov , Reinhard Klement \& Thomas M. Jovin

To cite this article: Anna K. Shchyolkina, Lyudmila E. Minchenkova, Elvira E. Minyat, Yelena B. Khomyakova, Valery I. Ivanov, Reinhard Klement \& Thomas M. Jovin (1998) Distamycinstabilized Antiparallel-Parallel Combination (APC) DNA, Journal of Biomolecular Structure and Dynamics, 15:5, 823-839, DOI: $10.1080 / 07391102.1998 .10508205$

To link to this article: http://dx.doi.org/10.1080/07391102.1998.10508205

曲 Published online: 21 May 2012.

Submit your article to this journal ¿

Џ Article views: 14

View related articles $\smile$

4 Citing articles: 1 View citing articles 주제 


\section{Distamycin-stabilized Antiparallel-Parallel Combination (APC) DNA}

http://www.albany.edu/chemistry/sarma/jbsd.html

\begin{abstract}
The formation of Antiparallel-Parallel-Combination (APC) DNA, a liner duplex with a segment of parallel-stranded (ps) helix flanked by conventional B-DNA, was tested with a number of synthetic oligonucleotides. The groove-binding ligand distamycin A (DstA) was used to stabilize the ps segment comprising five A.T base pairs. Two drug molecules bound per APC, one in each of the two equivalent grooves characteristic of ps-DNA. APC-DNA, reference molecules and their complexes with DstA were analysed by several methods: circular dichroism and absorption spectroscopy, thermal denaturation, chemical modification, and molecular modeling. The dye binding stoichiometry differed significantly due to inherent structural differences in the groove geometries of ps-DNA (trans base pairs, similar grooves) and conventional antiparallel-stranded (aps) B-DNA (cis base pairs, distinct major and minor grooves). The data support the existence of APC folding in solution.
\end{abstract}

\section{Introduction}

The existence of stable DNA duplexes with strands oriented parallel to each other is well documented (1-6) and leads immediately to a consideration of mechanisms by which this conformation can arise from B-DNA. General schemes for such interconversions have been presented in numerous publications $(2,3,7-10)$. One question in particular relates to the potential types of junctions demarcating a parallel-stranded (ps) segment from flanking antiparallel B-DNA. Ulyanov and colleagues (11) have proposed a molecular model for a possible structure incorporating aps-ps-aps segments (Figure 1). This novel conformation has been denoted Antiparallel-Parallel Combination (APC) DNA; a theoretical conformational study will be published elsewhere (N. B. Ulyanov, V. B. Zhurkin, R. H. Sarma, and V. I. Ivanov, in preparation). Ivanov and colleagues designed and synthesized oligonucleotides with sequences predisposing the establishment of the APC structure (Figure 2A). The potential for forming the unique parallel/antiparallel APC junction in the intramolecular tertiary structure of the oligonucleotide APC-33 as well as in the intermolecular duplex arising from the separate strands M1 and M2 is the topic of the communication.

Preliminary experiments with chemical modification (12) have shown that the proposed ps region in APC-DNA does not possess the stability required for resisting modification by osmium tetroxide or diethylpyrocarbonate, reagents specific for exposed thymines and adenines, respectively. With this in mind, we derived a strategy for providing additional stabilization of the putative ps helical segment composed of trans $\mathrm{d}(\mathrm{A} \cdot \mathrm{T})$ base pairs, by binding the antibiotic distamycin A (DstA). This drug is specific for AT sequences of conventional B-DNA and interacts with the minor groove (13-15), making both hydrogen bonding and van der Waals contacts with both strands $(16,17)$. We anticipated that this ligand would distinguish between the ps and aps helical segments, a consideration based on the peculiarities of the groove geometry of ps-DNA $(18,19)$, in which the trans configuration of the

\author{
Anna K. Shchyolkina1, \\ Lyudmila E. Minchenkova ${ }^{1}$, \\ Elvira E. Minyat ${ }^{1}$, \\ Yelena B. Khomyakova ${ }^{1}$, \\ Valery I. Ivanov1, \\ Reinhard Klement ${ }^{2}$ \\ and Thomas M. Jovin ${ }^{2 *}$ \\ 'Engelhardt Institute of \\ Molecular Biology, \\ Russian Academy of Science, \\ 117984 Moscow, Russia, \\ 2Department of Molecular Biology, \\ Max Planck Institute for \\ Biophysical Chemistry, \\ D-37070 Göttingen, FRG
}

*Author to whom correspondence should be addressed. Phone: +49-551-2011381; Fax: +49-551-2011467;

E-mail: tjovin@mpc186.mpibpc.gwdg.de. 


\section{Shchyolkina et al.}

Figure 1: Stereopair representation of the energy minimized molecular model for APC. Note that the axes of both helical conformations are mutually perpendicular. One can perceive the left tums at the junctions between parallel and antiparallel helices. The structure was computed by N. B. Ulyanov and colleagues (Ivanov et al., 1993); further details will be published elsewhere.

A

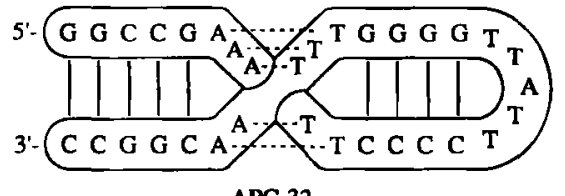

APC-33

B

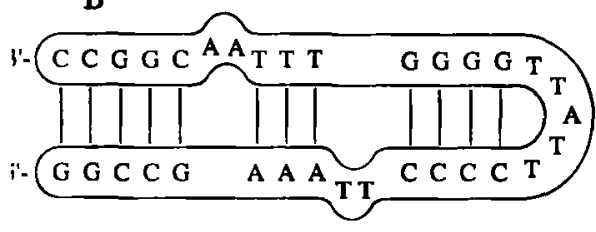

hp-33

C

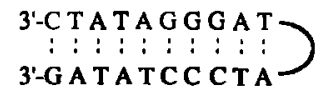

ps-N1

3'-A A A A A A A A A A $\mathrm{C}_{\mathrm{C}}$

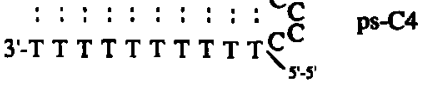

S'-A T A T A T A T A T IIIII I I I I I 3'-T A T A T A TATA
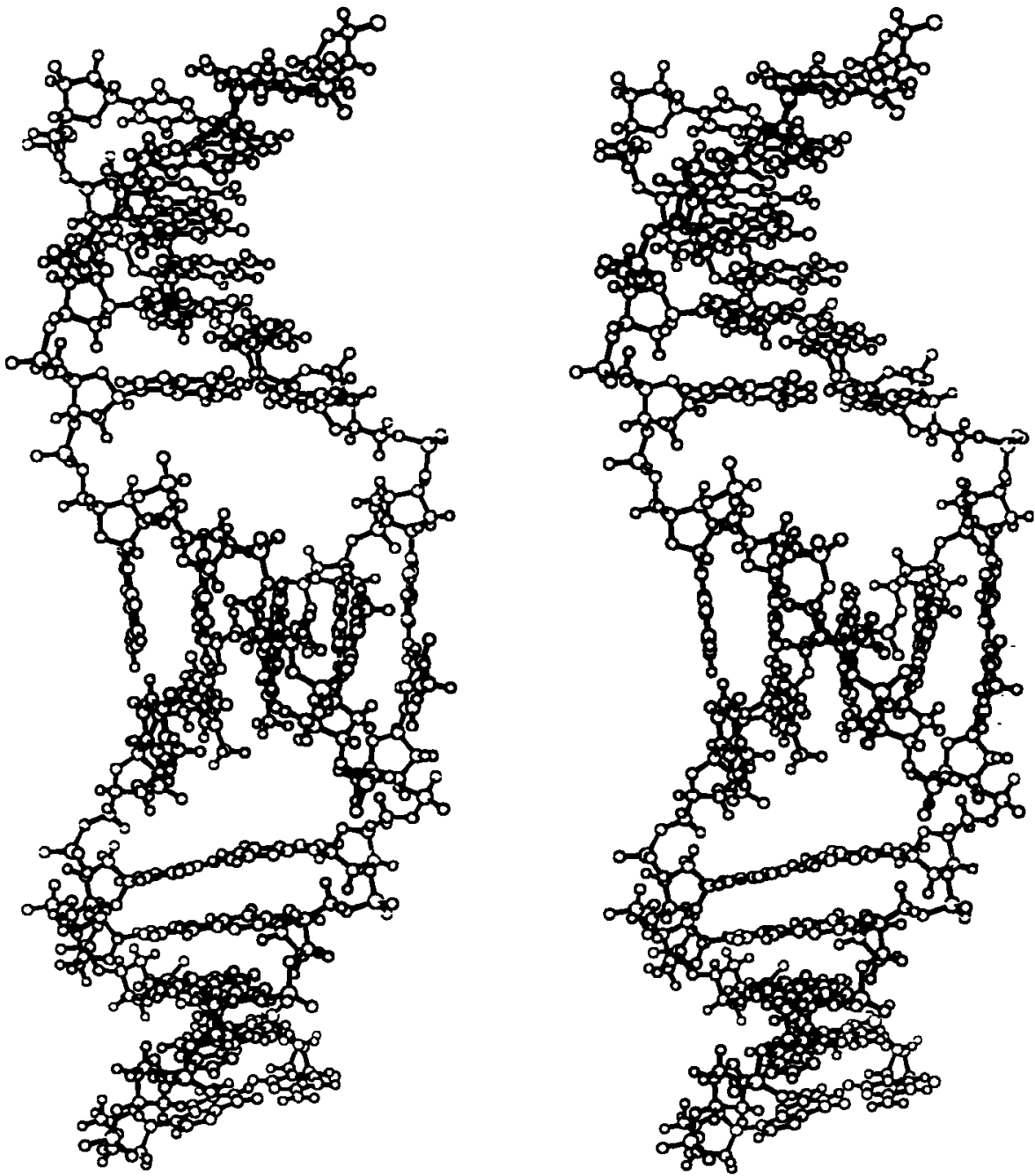

A.T base pairs insures that the widths of the two grooves are similar and intermediate between that of the major and minor grooves of B-DNA.

$\mathrm{X}$-ray crystallographic analysis has demonstrated that the hydrogen bonding acceptors associated with the two strands of conventional B-DNA (N3 atoms of adenine and $\mathrm{O} 2$ atoms of thymine) participate in ligand binding $(16,17,20)$. However, the number of hydrogen bonding donor and acceptor groups in each groove of ps-DNA depend on the sequence, as exemplified by a segment with all adenines in one strand and all thymines in the other [homopurine(A)-homopyrimidine(T) ps hairpin ps-C4 (Materials)]. The two grooves have a different number of acceptor groups (Figure 3), leading to differences in binding potentials for DstA.

On the other hand, ps-DNA with an alternating (or non-regular) AT sequence presents the $\mathrm{N} 3$ of adenines and $\mathrm{O} 4$ of thymines in both grooves (Figure 3). In such a case, the expected binding stoichiometry for DstA would be twice that of B-DNA, i.e. two instead of one drug molecule per $4-5$ base pairs $(14,15)$. We base this assumption on the known features of the DstA complexes with B-DNA and the fact that the B-type backbone configuration is preserved in the two strands constituting ps-DNA $(18,19,21)$. However, the situation is potentially more complex, inasmuch as B-DNA is able to accommodate two DstA molecules side-by-side in the minor groove of certain sequences $(16,22,23)$. These considerations motivated a detailed study of the interaction of DstA with the APC construct, the results of which are

Figure 2: Schemes for the secondary-tertiary structure of the oligonucleotides. (A) APC type of folding the APC-33 oligonucleotide with a central ps region (stippled base pairs). (B) Alternative hairpin hp33 structure with bulges of the APC-33 oligonucleotide. (C) Intramolecular hairpin structures for the ps$\mathrm{N} 1$, ps-C4 and antiAT oligonucleotides. 
The following deoxyoligonucleotides were synthesized and purified as described Combination (APC) DNA previously $(24,25)$.

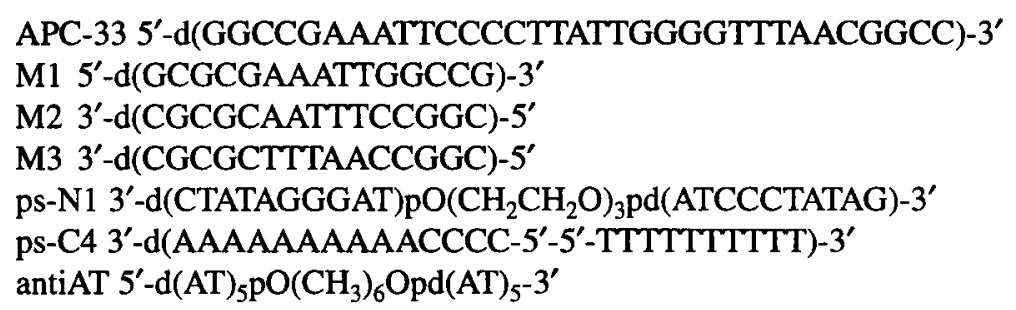

Schemes for the secondary structures of the APC-33, ps-N1, ps-C4 and antiAT oligonucleotides are presented in Figure 2. Ps-C4 has been studied previously (1). Ps-N1 was synthesized and purified by Dr. G.E. Pozmogova and by Eppendorf Biotronik (Berlin). The detailed characterization of the ps-N1 and other ps GC-containing hairpins will be presented elsewhere (A. Shchyolkina, O. Borisova, G. Pozmogova, R. Klement, T. M. Jovin, in preparation). AntiAT was synthesized and purified by Dr. B.K. Chernov (5). All oligonucleotides were purified by HPLC and desalted.

\section{Preparation of DNA and DstA-DNA Samples}

Oligonucleotide concentrations were determined as follows. The measured absorbances at $260 \mathrm{~nm}, 90^{\circ} \mathrm{C}, \mathrm{pH} 7.0$ were increased by $20 \%$ to take into account residual hypochromicity, and molar concentrations in nucleotide units were computed using a mean molar extinction coefficient per residue for the individual oligonucleotides (24). The concentrations determined by this procedure were in good agreement with those obtained by hydrolysis of the oligonucleotides with snake venom phosphodiesterase (24). The M1·M2 and M1.M3 duplexes were formed by mixing equimolar solutions of the single strands; all the samples were heated to $90^{\circ} \mathrm{C}$ and cooled slowly. It should be emphasized that the APC-33, antiAT, ps-N1, and ps-C4 concentrations were adjusted to an oligonucleotide concentration of $0.5-0.8 \mu \mathrm{M}$, low enough to shift the equilibrium towards the formation of intramolecular hairpins with a concomitant minimization of intermolecular structures (5). In contrast, the concentrations of $\mathrm{M} 1 \cdot \mathrm{M} 2$ and $\mathrm{M} 1 \cdot \mathrm{M} 3$ were maintained in the range of 5-10 $\mu \mathrm{M}$ in order to favor duplex over hairpin structures. Aqueous solutions of DstA (Pharmitalia or Sigma) were prepared daily. The molar extinction coefficient was taken as $30 \mathrm{mM}^{-1} \mathrm{~cm}^{-1}$ at $303 \mathrm{~nm}$ (26). Unless stated otherwise, the experiments were carried out at $1-3^{\circ} \mathrm{C}$ in $0.01 \mathrm{M} \mathrm{Na}$-phosphate buffer, $\mathrm{pH}$ 7.0. The low ionic strength was selected so as to increase the affinity of the DstA for the oligonucleotides.

\section{$C D$ and $U V A$ Asorption Spectroscopy}

Ultraviolet absorption spectra and thermal denaturation curves were recorded with a Uvikon 820 spectrophotometer (Kontron) equipped with a computer-controlled thermostated cuvette holder and data acquisition (25), or with a Beckman 25 spectrophotometer. Heating was either discontinuous with equilibration for 1 every 2 min (Uvikon) or at a constant rate of $0.2 \% \mathrm{~min}$ (Beckman). Analysis was in terms of two-state transition models for either duplex (27) or hairpin (E. Evertsz and T. M. Jovin, manuscript submitted for publication) molecules.

Circular dichroism (CD) spectra were acquired with Jasco-720 spectropolarimeter 


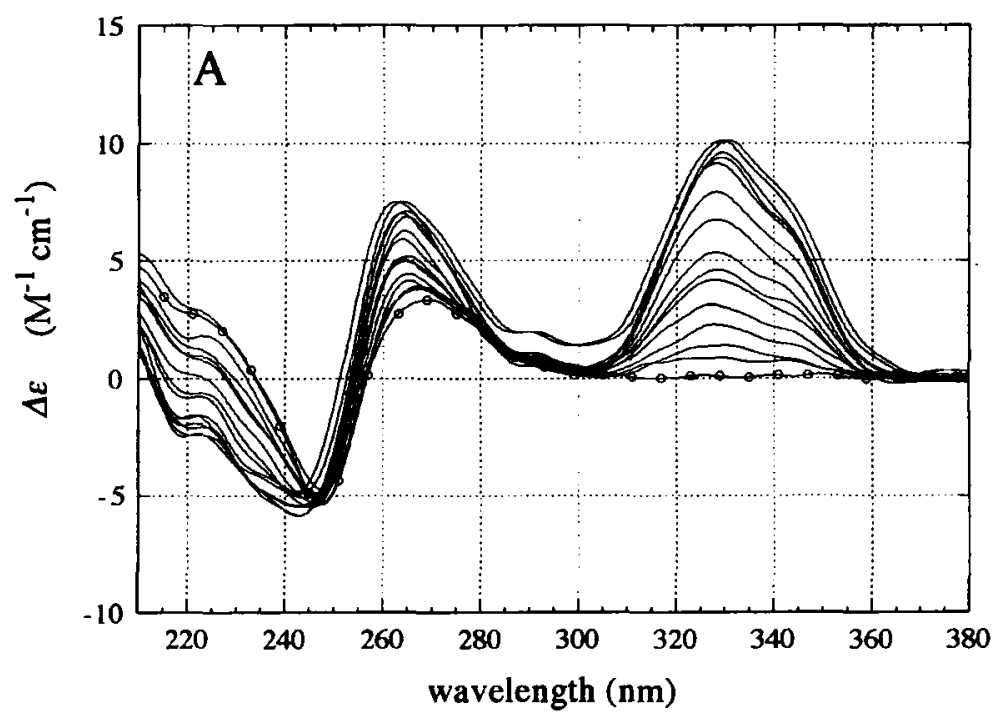

\section{Shchyolkina et al.}

Figure 4: $C D$ spectra of antiAT $(A)$ and ps-N1 $(B, C)$ at different DstA concentrations. (A) DstA/oligonucleotide: 0 (marked line), $0.09,0.17,0.35,0.52,0.70$, $0.87,1.14,1.40,1.66,1.92,2.19,2.7,3.2,4.35$; (B) DstA/oligonucleotide: 0 (marked line), $0.18,0.35$, $0.53,0.7,0.88,1.06,1.23,1.41,1.58,1.76,1.94$; (C) DstA/oligonucleotide: 1.94 (marked line), 2.29, 2.46 $2.82,3.17,3.6,4.0,4,48,4.92$. Temperature, $I^{\circ} \mathrm{C}, 10$ $\mathrm{mM} \mathrm{Na}$-phosphate buffer, $\mathrm{pH} 7$ and 7.5 . Concentrations: [antiAT hairpin], $0.54 \mu \mathrm{M}$; [ps-N1 hairpin], $0.6 \mu \mathrm{M}$
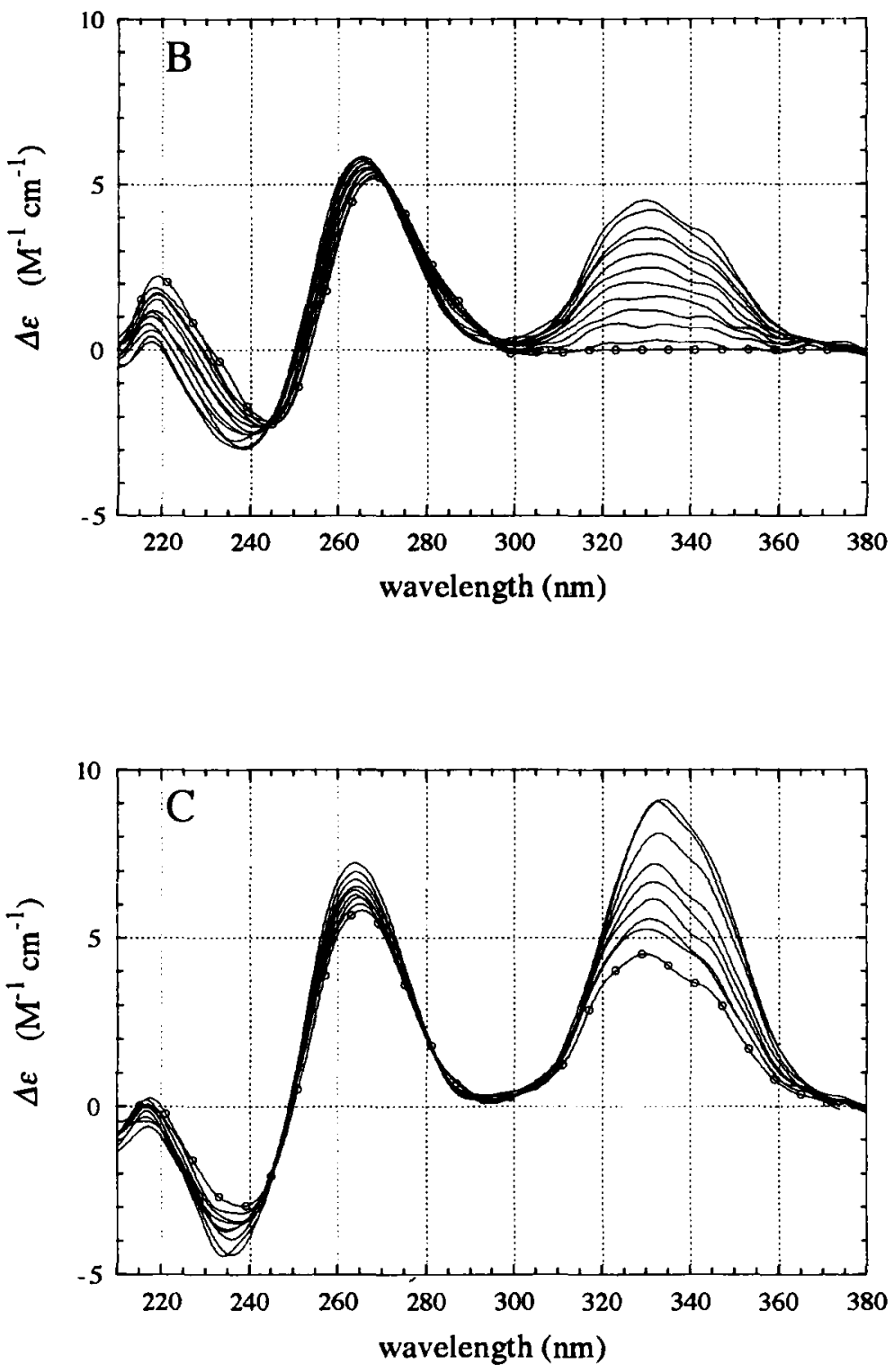


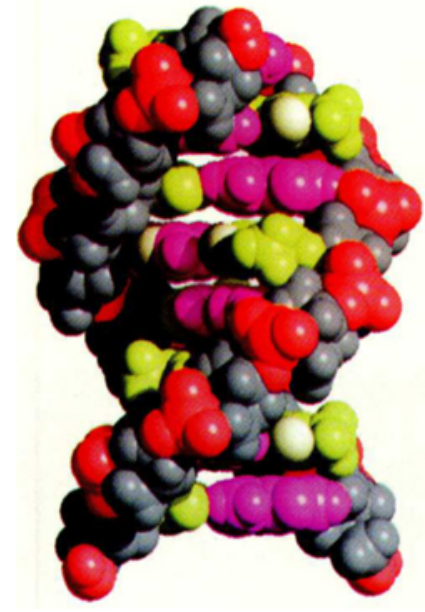

ps d(AT) $)_{4} \cdot \mathrm{d}(\mathrm{TA})_{4}$

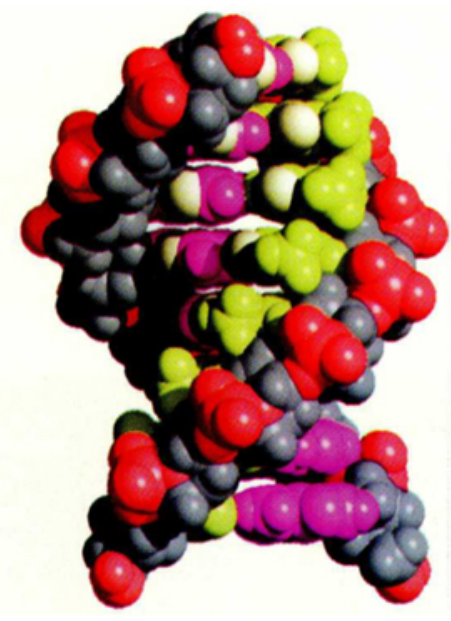

ps $d(A)_{8} \cdot d(T)_{8}$

Figure 3: Model structures of ps-DNA with the sequence $d(A T)_{4} \cdot d(T A)_{4}$ (left) and $d(T)_{8} \cdot d(A)_{8}$ (right). Color coding: Adenine, magenta; thymine, yellow; deoxyribose, gray; phosphate group, red; N3(A) of adenine and O4(T) of thymine, light green. In the case of the homopolymer the pattern of $\mathrm{N} 3$ and $\mathrm{O} 4$ positions is only found in one groove, whereas in the alternating conformer $\mathrm{N} 3(\mathrm{~A})$ and $\mathrm{O} 4(\mathrm{~T})$ are present in both grooves.

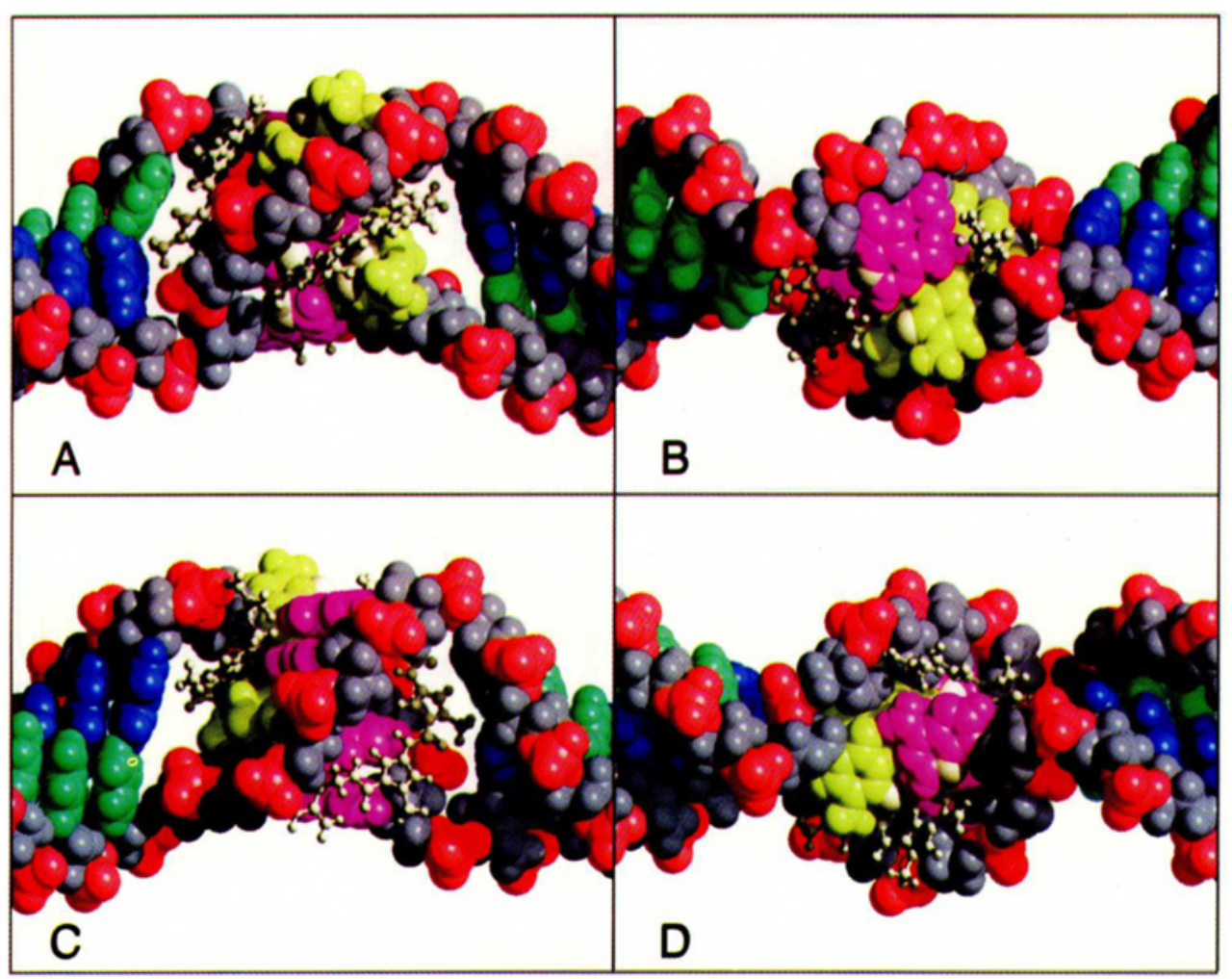

Figure 11: Central part of the APC;2DstA complex, Color coding as in Figure 3; Dst, light green. (A) and (C) side views [the helix axis of the d(TTTAA) section is parallel to the drawing plane] of the p-DNA section with the $5^{\prime}$ end on the bottom and the $3^{\prime}$ end on the top. Top view of the os section (the helix axis points inte the drawing plane) from the $z^{\prime}$ end (B) and from the $y^{\prime}$ end (D). The DstA molecules are oriented in an antiparallel fashion, with the charged ends pointing to the $3^{\prime}$ and $5^{\prime}$ positions. 


\section{Shchyolkina et al.}

Figure 12: Hydrogen bonding scheme of the two DstA drugs positioned within the two strands of the ps segment of APC. The stereo image in the upper part of the figure was generated from coordinates generated during a modelling procedure (see text for further details). The bases and sugars are shown as plates (adenine: magenta; thymine: yellow). The phosphates are missing and instead the backbone is represented by two ribbons with an arrow head on the $3^{\prime}$ end. The DstA drugs (light green) are depicted as stick models. The hydrogen bonds found between the drugs and the DNA are added as broken white bonds. The atoms involved in these hydrogen bonds are shown in detail in the schematic drawing in the lower part of the figure.
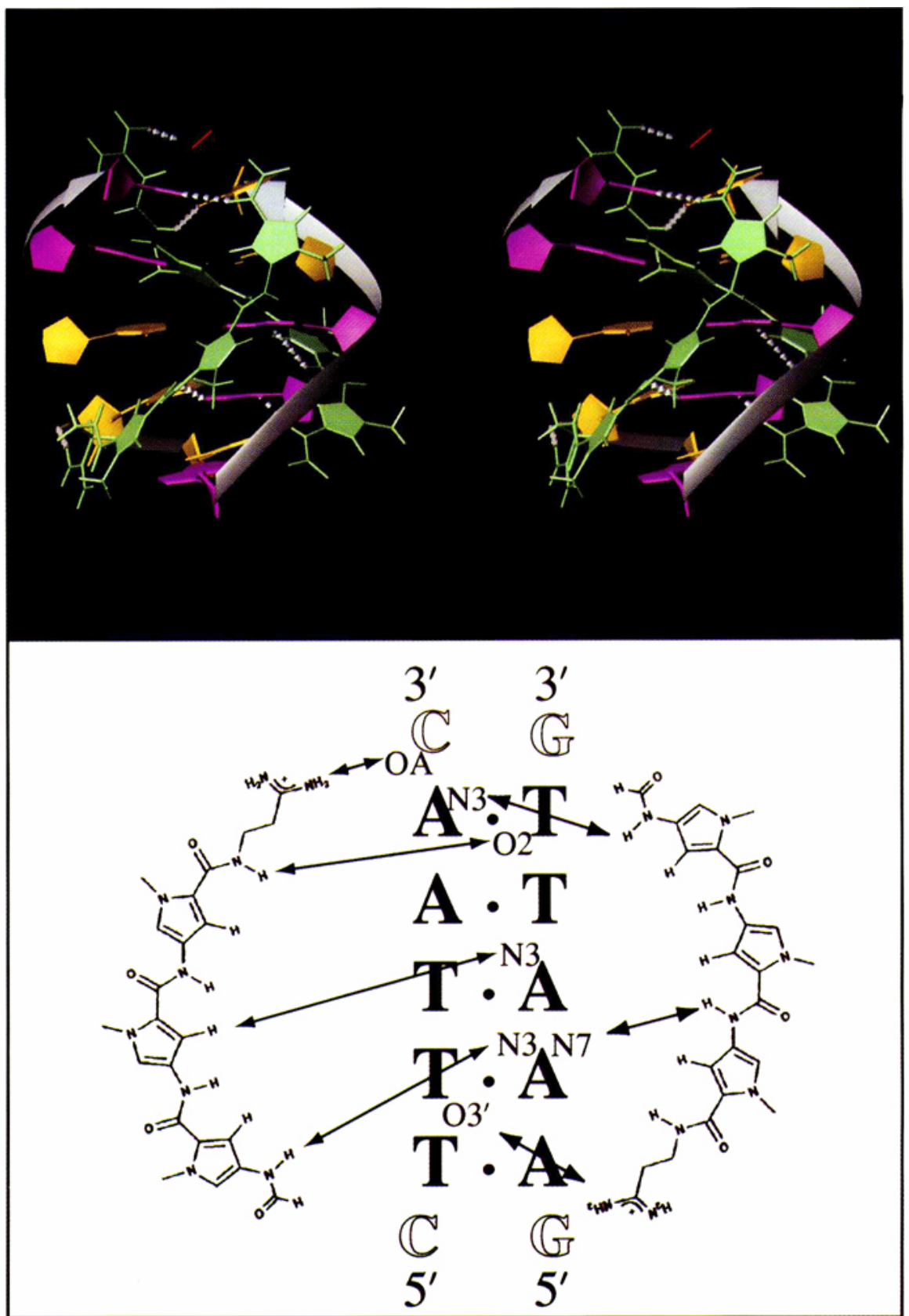
with a thermostated cuvette holder. The experimental data were analyzed and plot-

ted on an Apple Macintosh computer with KaleidaGraph (Abelbeck).

\section{Chemical Modification}

Chemical modification with pyridine-O $\mathrm{OSO}_{4}$ and enzymatic digestion with $\mathrm{S} 1$ nuclease were performed as described previously (28). Sequencing was carried out by the Maxam-Gilbert procedure (29). The autoradiograms were scanned with a Molecular Dynamics 300A Computing Densitometer.

\section{Molecular Modeling}

The model of the APC DNA molecule was provided by N.B. Ulyanov (11). Distamycin A coordinates were taken from crystal structure determination (30). AMBER parameters for DstA where kindly provided by S. B. Singh (31). The color figures were generated with the SCHAKAL92 program of E. Keller, University of Freiburg, Germany (32). Other details are given in Results and Discussion. The color stereo image of Figure 12 was generated with the program MOLMOL 2.2.0 of Reto Koradi at the ETH Zürich, Switzerland.

\section{Results and Discussion}

\section{$C D$ Patterns of DstA Binding to ps and aps-DNA}

The differential binding of DstA to conventional aps-DNA and to putative APCDNA, particularly those reflected in the drug/DNA stoichiometry, motivated a comparative study of DstA interactions with hairpins having specific DstA-binding sites but differing in strand orientation: antiAT and ps-N1 (Materials). At sufficiently low concentrations, $<0.5-1 \mu \mathrm{M}$, these oligonucleotides have been shown to form mainly intramolecular double helices without admixtures of intermolecular duplexes ( 5 and Shchyolkina et al., in preparation). Thus, the strand orientation is unequivocally determined by the primary structures of the oligonucleotides under the experimental conditions used. At higher DNA concentrations favoring the bimolecular formation of duplexes from separate strands, the groove-binding ligands DstA and netropsin have been shown to induce the reorientation of parallel oriented 25-nt strands and the formation of alternative aps duplexes incorporating mismatches (33). For this reason intramolecular double helical hairpins were used in this study as convenient models for investigating ps helix/ligand interactions.

The changes in the CD spectra of antiAT and ps- $\mathrm{N} 1$ upon addition of DstA are shown in Figure 4. The CD spectra of the ps-N1 at different concentrations of DstA revealed two different $C D$ patterns with characteristic isodichroic points at 245 , 270 and $292 \mathrm{~nm}$ (Figure 4B) and at 247 and $282 \mathrm{~nm}$ (Figure 4C). The CD changes at DstA/hairpin ratios $>2$ were indicative of a weak DstA.ps-NI complex that could be easily displaced by $\mathrm{NaCl}$ addition (see below, Figure 6) and presumably reflected interactions with $G C$ regions or phosphate groups $(14,15)$. The distinct isodichroic points of the CD pattern for tight specific binding of up to two DstA molecules to ps-Nl (Figure 4B) suggested that (i) the binding of each DstA molecule induced the same CD changes and (ii) only two distinct forms of ps-N1, free and bound to DstA, were present in the sample.

\section{Patterns of DstA Binding to APC and MI.M2}

Two samples were potentially capable of forming a segment of 5 base pairs in a parallel-stranded orientation: APC-33 and M1-M2. Figures 5A, B show the changes in the CD spectra upon addition of DstA to solutions of APC and M1.M2, respectively. A comparison of the CD difference spectra for the complexes of DstA/APC$33=2$ and DstA/M1 $\cdot \mathrm{M} 2=2$ (Figures 5C,D) revealed major similarities. The dif- 
ference absorption spectra (Figure 5E,F) provided additional evidence for the

\section{Shchyolkina et al.} equivalence of the $2: 1$ DstA complexes with APC and M1·M2, despite the presence of the end loop in APC-33 and some differences in the sequence of the flanking aps GC regions.
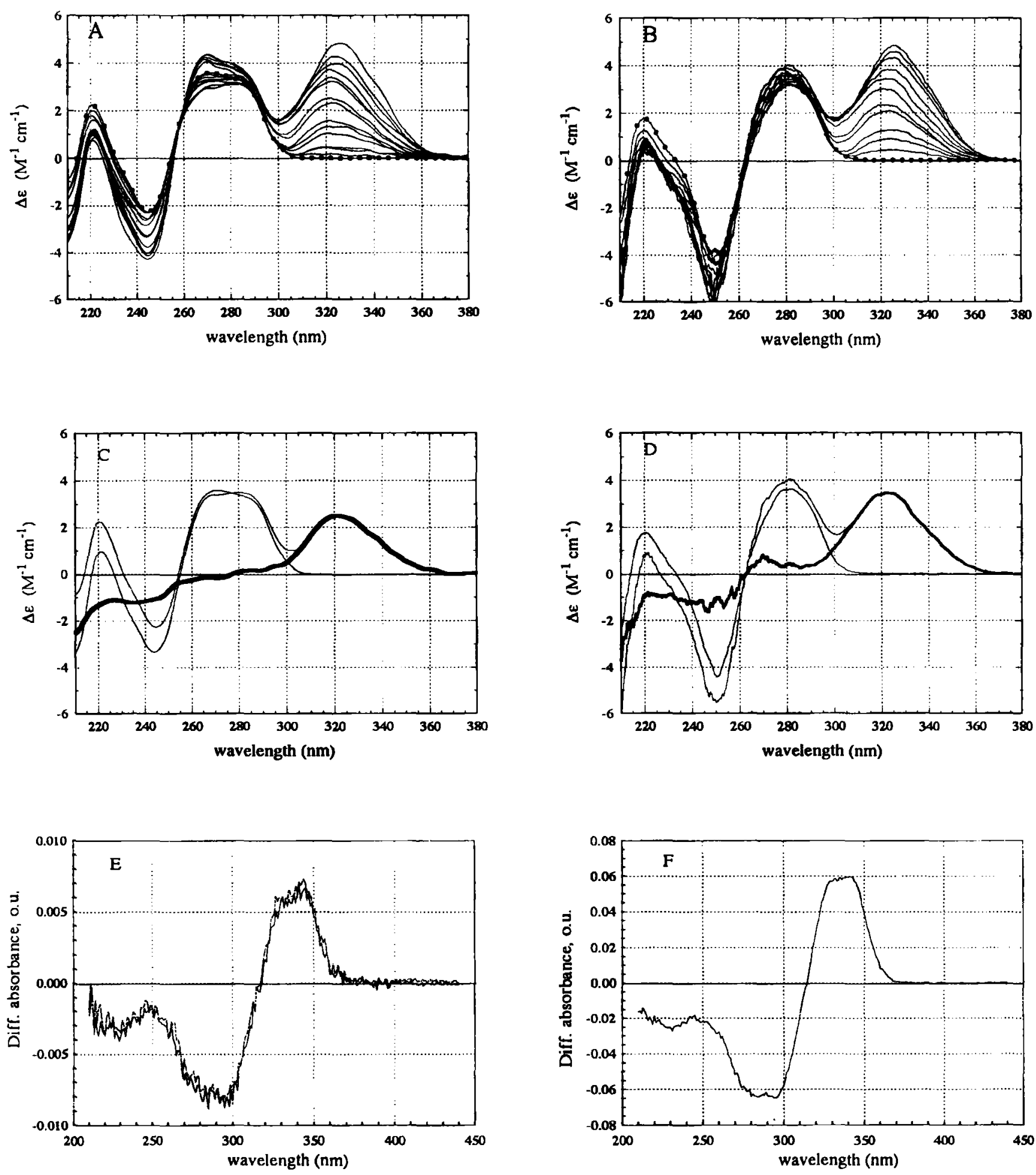

Figure 5: CD spectra of oligonucleotides APC-33 and M1-M2 at different DstA concentrations. (A) DstAoligonucleotide (APC): 0 (marked line), $0.13,0.26,0.4$, $0.7,1.0,1.3,1.7,2.0,2.3,2.6,3.0,3.6,4.2,4.8$. (B) DstA/oligonucleotide (M1-M2): 0 (marked line), $0.2,0.41 ., 0.61,1.02,1.22,1.63,1.83,2.04,2.44,2.85,3.05$, 4.0. CD spectra (thin lines) and difference CD spectra (thick lines) for DstAvoligonucleotide $=2$, for APC-33 (C) and M1 M2 (D). Difference absorption spectra of complexes of APC-33 (E) and M1 M2 (F) saturated with DstA (complex - free DNA). Note that despite a ten-fold difference in the concentrations of intramolecular (APC-33) and intermolecular (M1-M2), the shapes of these curves are identical, including the fine details. [APC], 0.64 $\mu \mathrm{M} ;$ [M1-M2 duplex], $10 \mu \mathrm{M}$. Temperature, $1^{\circ} \mathrm{C} ; 10 \mathrm{mM} \mathrm{Na}$-phosphate, $\mathrm{pH} 7$ and 7.5 . 
The titration curve for APC-33 (Figure 6A) derived from the CD data in Figure 5A had only one breakpoint, corresponding to a stoichiometry of $2: 1$; the CD signal increased monotonically upon subsequent addition of more DstA. The latter phenomenon most probably reflected weak non-specific complexes with the GC regions of the oligonucleotide $(14,15)$. An increase in the $\mathrm{NaCl}$ concentration above $0.2 \mathrm{M}$ removed completely the $\mathrm{CD}$ effects at drug/DNA ratios $>2$ (Figure $6 \mathrm{~B}$ ). The titration curve for the reference hairpin ps-N1 (Figure $6 \mathrm{C}$ ) revealed the same stoichiometry of specific DstA binding; the complexes formed at DstA/hairpin $>2$ were displaced by $\mathrm{NaCl}$ addition (Figure 6D). The incremental $\mathrm{CD}$ changes upon binding of the first and the second DstA to the single ATAT binding site were equal. The maximum numbers of tightly bound DstA molecules per single 4-5 bp AT-containing binding site for ps and aps oligonucleotides are presented in the Table I. As stated in the Introduction, the hairpin ps-C4 (see Materials) would be expected to bind only half the number of ligand molecules per 4-5 bp site compared to the ps-N1 sample with the alternating sequence (Figure 3 ). This prediction was verified (Table I). The stoichiometry and the CD changes (data not shown) accompanying DstA binding to ps-C4 testifies to the monomeric character of DstA binding to parallelstranded non-alternating A-T sequences, an observation in agreement with data on netropsin binding to the ps-C4 hairpin (34).

Our interpretations of DstA binding to the set of oligonucleotides used in this study were based on the assumption that the tight salt-resistant complex represents groove binding in AT sequence segments (rather than to GC stems) and that the Bbackbone disposition of ps-DNA preserves the features of DstA complexes with BDNA, such as hydrogen bonding to 4 successive nucleotides.
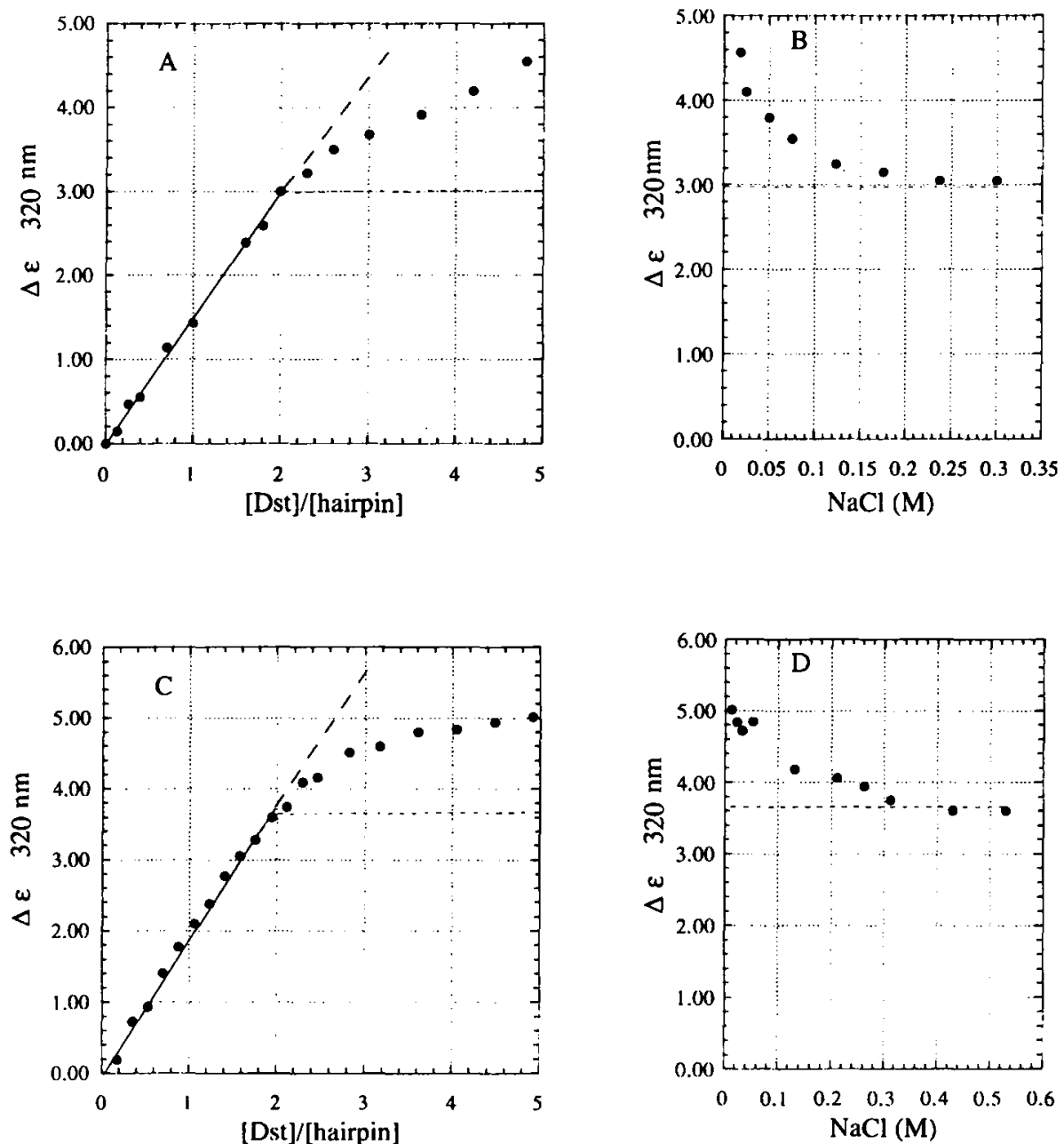

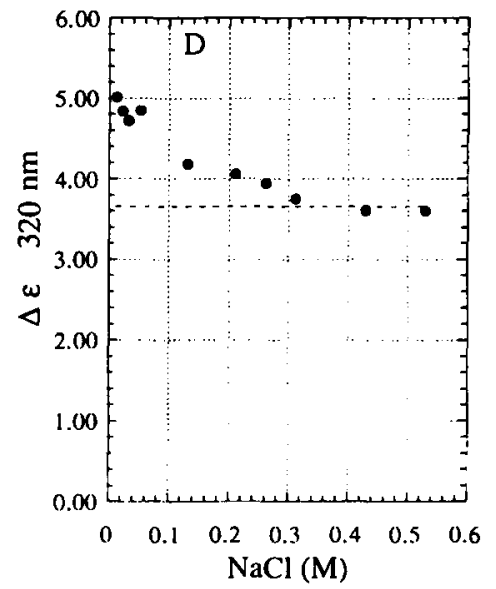

Distamycin-stabilized Antiparrallel-Parrallel Combination (APC) DNA
Figure 6: Titration of APC-33 and ps-NI with DstA and effect of added $\mathrm{NaCl}$. (A) Titration of the oligonucleotide APC-33 with DstA. (B) Competitive titration with $\mathrm{NaCl}$ of DstA-saturated complex of APC. (C) Titration of the oligonucleotide ps-N1 with DstA. (B) Competitive titration with $\mathrm{NaCl}$ of DstAsaturated complex of ps-N1. Other conditions as in Figures 5 (for APC) and 4 (for ps-N1). 


\section{Shchyolkina et al.}

Figure 7: $\mathrm{CD}$ spectra of M1.M3 duplex in solution at different DstA concentrations. Temperature, $1^{\circ} \mathrm{C}$; $10 \mathrm{mM} \mathrm{Na}$-phosphate, $\mathrm{pH}$ 7. (A) DstA/duplex concentration: 0 (marked line), $0.11,0.21,0.32,0.42$, $0.53,0.64,0.74,0.85,0.95,1.06$. (B) DstA/duplex: $1.06,1.17,1.27,1.48,1.7,1.91,2.1,2.44,2.76,3.07$, 3.5. [M1.M3 duplex], $10 \mu \mathrm{M}$.
Groove

In order to clarify the possible structural basis for the $2: 1$ stoichiometry of DstA binding to to APC, M1·M2, and ps-N1 we studied DstA binding to the aps M1·M3 duplex. Wemmer et al. (23) have shown that the formation of 2:1 DstA dimers with aps deoxyoligonucleotides depends strongly on nucleotide sequence. They observed the formation of 2:1 complexes of DstA with a AAATT.AATTT duplex binding site at a ligand/site ratio of 2:1.

The titration of the M1.M3 duplex with DstA was followed by CD (Figure 7). Two distinct binding phenomena were evident. The first corresponded to a DstA/duplex ratio of $0-1$, and was characterized by increasing dichroism in the regions of 220$240 \mathrm{~nm}$ and $310-360 \mathrm{~nm}$ and an isodichroic point at $309 \mathrm{~nm}$ (Figure 7A). The binding was stoichiometric, i.e. of very high affinity. In the second stage of the titration an additional drug molecule bound to the DNA, leading to more complex changes in the CD spectra in the $210-180 \mathrm{~nm}$ region, with isodichroic points at 289 and 314 $\mathrm{nm}$ (Figure 7B) and increasing dichroism at $320-360 \mathrm{~nm}$. The distinct but different isodichroic points attested to the participation of only two components in each of the two stages of the titration. Both the monomeric and dimeric complexes were specific, as evidenced by their resistance to dissociation by salt (up to $3 \mathrm{M} \mathrm{NaCl}$ ). This property is characteristic for the specific complexes of DstA with AT-sites in B-DNA (13-15). The CD changes accompanying the formation of the dimeric com-
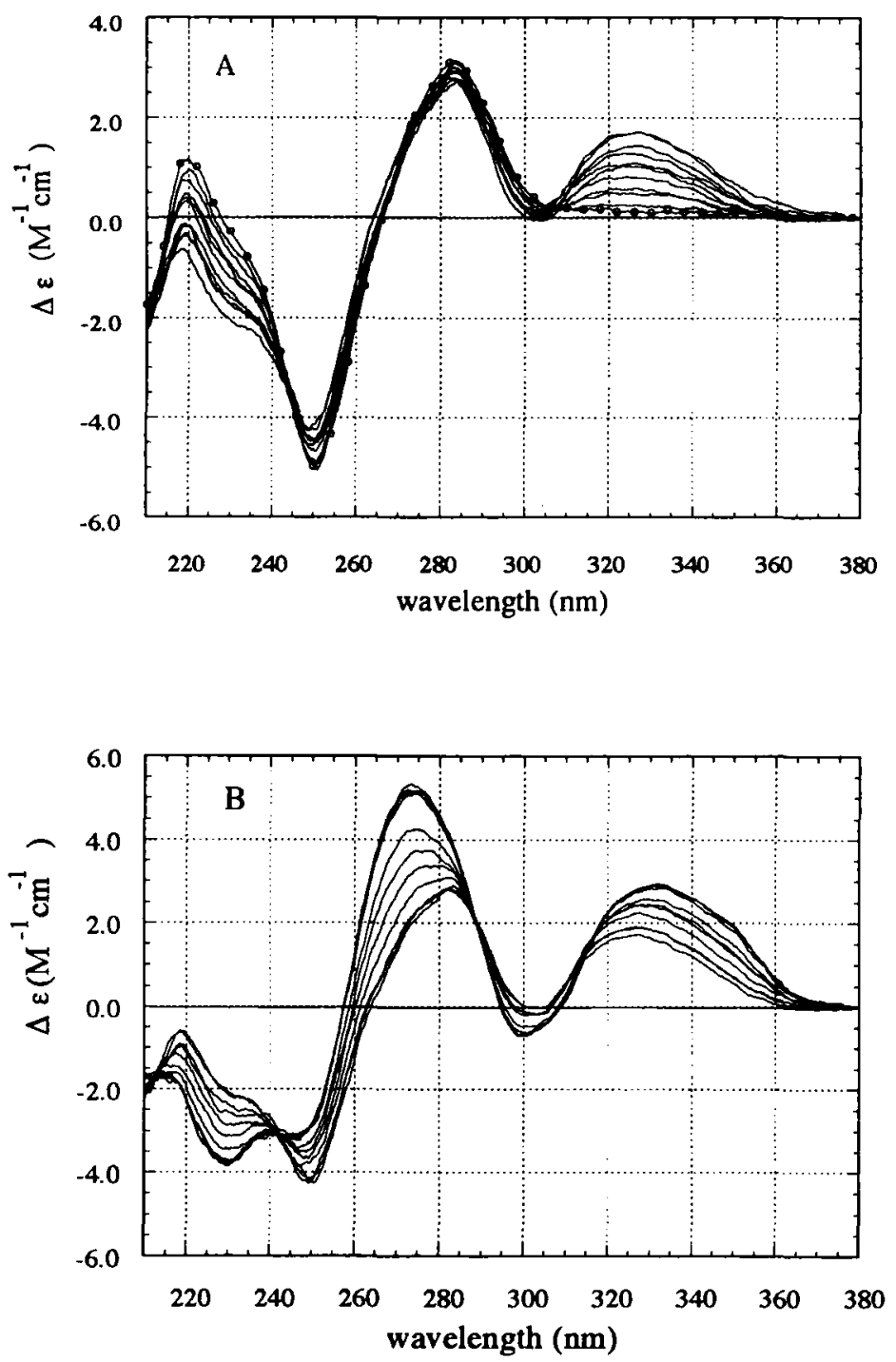
plex at $270 \mathrm{~nm}$ and in the longer wavelength region ( $>350 \mathrm{~nm}$ ) were distinctive and constitute a spectral signature for this species. The specific features of the $C D$ signal are induced by head-to-tail side-by-side dimerization of DstA molecules into one of the grooves (23).

The above CD spectra were not obtained with the DstA complexes of APC-33, $\mathrm{M} 1 \cdot \mathrm{M} 2$, ps-N1, and ps-C4. Moreover, for APC-33, M1·M2, and ps-N1 the shapes of the $\mathrm{CD}$ curves for the $1: 1$ and 2:1 tight complexes with DstA were similar (Figures 4B, 5). In these cases we observed no spectral distinction between the 1:1 and 2: 1 complexes. In addition, we note that the $C D$ spectra of the tight 2:1 DstA complexes of APC-33 and M1-M2 (Figures 5C,D) were very similar to that of the monomeric 1:1 DstA complex with the control aps duplex M1·M3 (Figure 7A). We conclude at this point that the complex of the drug with aps-DNA (M1-M3) was fundamentally different from that with ps-DNA (the [5'-d(AAATT)-3'] $\left[5^{\prime}\right.$ d(TTTAA)-3'] segment in APC-33 and the M1.M2 duplex), the latter corresponding to a strong complex with a stoichiometry of $2: 1$.

The presumption is that DstA binds monovalently into each of two grooves of the ps ATAT site. Molecular modelling suggests a structural basis for this conclusion: the location of the methyl groups of thymines in the grooves of ps AT stretches block the side-by-side dimerization of ligands in the groove (Figure 3; see also Figure 11). In addition, the two DstA molecules in the $2: 1$ complexes with B-DNA are in an anti-parallel orientation, thereby achieving symmetrical contacts with their respective bounding DNA strands $(16,23)$. Such a circumstance cannot arise with ps-DNA.

An alternative explanation for the observed stoichiometry of the Dst binding to the APC oligonucleotide may be considered. It should be noted that oligonucleotides APC-33 and M1.M2 are able to form alternative structures with mismatches and several (maximum three successive) conventional Watson-Crick A.T base pairs (Figure 2B). One cannot exclude a priori the possibility of a DstA dimer binding to such discontinuities in the sequence. However, this supposition is not consistent with the $C D$ data. The $C D$ pattern of the side-by-side dimer results from specific arrangement of the Dst molecules effecting the induced CD signal, and from possible changes in the DNA structure due to the widening the groove. Thus, the absence of the specific $C D$ changes accompanying the binding of a second Dst molecule to the APC argues against this possibility. Furthermore, the experiments with chemical probes described below refute the presence of alternative oligonucleotides structures with mismatches in the complexes of APC-33 and M1-M2 with DstA.

\section{Affinity of DstA for APC, ps-NI and antiAT}

In the above experiments, low ionic strength solutions were chosen for the quantitative determination of the DstA binding stoichiometries. For the assessment of binding affinities similar binding experiments were performed at $0.6 \mathrm{M} \mathrm{NaCl}$. Titration curves were constructed using experimental values $\Delta \mathrm{D}$, the incremental CD signal at $320 \mathrm{~nm}$, for different total concentrations of added DstA (Figure 8). The experimental data were fit to the equations $\Delta D=f([D s t A])$ (see legend to Figure 8) based on the following mass action equations.

$$
\begin{gathered}
K_{1, \text { ass }} \\
\text { hairpin + DstA } \leftrightarrow \text { hairpin } \cdot \text { DstA } \\
K_{2, \text { ass }} \\
\text { hairpin - DstA + DstA } \leftrightarrow \text { hairpin - 2DstA }
\end{gathered}
$$

Inasmuch as the incremental $C D$ changes upon binding the first and second Dst $A$ molecules were shown to be equal (Figures 4-6), the assumption was made that the 


\section{Shchyolkina et al.}

Figure 8: Titration of APC-33 (A), ps-NI (B), and antiAT (C) with DstA in $0.6 \mathrm{M} \mathrm{NaCl}$. Ordinate: $\Delta D$, the experimental incremental dichroism values at $320 \mathrm{~nm}$. Abscissa: molar concentration of added DstA. Conditions: temperature, $1^{\circ} \mathrm{C} ; 10 \mathrm{mM} \mathrm{Na}$ phosphate, $\mathrm{pH} 7$; [APC-33 hairpin], $0.4 \mu \mathrm{M}$; [ps-N1 hairpin], $0.6 \mu \mathrm{M}$; [antiAT hairpin], $0.72 \mu \mathrm{M}$. Curves were fit to the equation for the mass action equilibrium where $C_{0}$ was the molar concentration of the binding sites. The assumption was made that that the molar $\mathrm{CD}, \Delta \varepsilon$, at $320 \mathrm{~nm}$ was equal for the first and second bound DstA molecules. (A) $C_{0}=$ hairpin concentration, $0.4 \mu \mathrm{M}$. (B) and (C) $C_{0}=2$ hairpin concentration (two binding sites/molecule), and the assumption was made that $K_{1, a s s}=K_{2, a s s}$. The derived parameters are given in Table I.
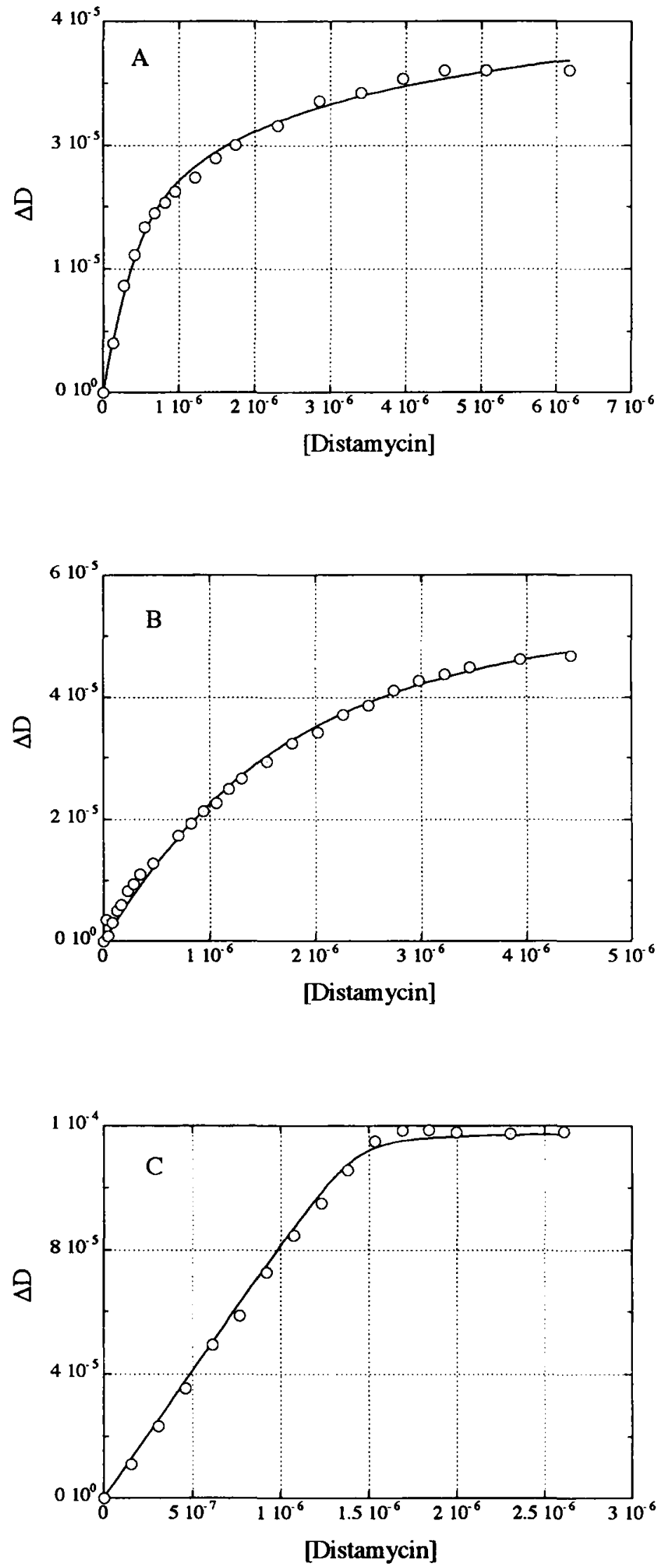
molar CD increments for the two steps (Eq. 1) were also equal. The calculated association constants are presented in Table I. For ps-N1 and antiAT, the values for the first and second DstA molecules were the same within experimental error. That is, binding of DstA into each of two identical grooves of the ps ATAT site of ps-N1 proceeds independently and with equal affinity. The affinity for antiAT was estimated as a lower limit due to the almost stoichiometric behavior (sharp bend) of the titration curve. The $K_{\text {ass }}$ for the ps site was approximately two orders of magnitude lower than that for the aps site. By way of comparison, the reported $K_{\text {ass }}$ for the groove binding ligand Hoechst 33258 in $0.4 \mathrm{M} \mathrm{NaCl}, \mathrm{pH} 7,10^{\circ} \mathrm{C}$ to the ps hairpin $3^{\prime}$-d(TTTTTTTT-5'-5'-CCCCAAAAAAAA)- $3^{\prime}$ was $8 \mu \mathrm{M}^{-1}$ and for the aps hairpin $5^{\prime}$ - d(TTTTTTTCCCCAAAAAAAA)-3' $550 \mu \mathrm{M}^{-1}$ (34).

Table I

Parameters of DstA Binding to Oligonucleotides

\begin{tabular}{|c|c|c|c|c|c|c|}
\hline DNA & $\begin{array}{l}\text { Number } \\
\text { of } 4-5 \mathrm{bp} \\
\text { binding } \\
\text { sites }\end{array}$ & $\begin{array}{c}\text { Maximum } \\
\text { number of } \\
\text { tightly } \\
\text { bound DstA } \\
\text { per site }\end{array}$ & $\begin{array}{c}\Delta \varepsilon^{*} \\
320 \mathrm{~nm} \\
\text { low salt } \\
\left(\mathrm{M}^{-1} \mathrm{~cm}^{-1}\right)\end{array}$ & $\begin{array}{c}\Delta \varepsilon^{*} \\
320 \mathrm{~nm} \\
0.6 \mathrm{M} \mathrm{NaCl} \\
\left(\mathrm{M}^{-1} \mathrm{~cm}^{-1}\right)\end{array}$ & $\begin{array}{c}K_{\mathrm{i}, a s s}^{\ddagger} \\
\left(\mu \mathrm{M}^{-1}\right) \\
0.6 \mathrm{M} \mathrm{NaCl}^{\circ} \mathrm{NaC} \\
1^{\circ} \mathrm{C}\end{array}$ & $\begin{array}{c}K_{2, a s s}^{\ddagger} \\
\left(\mu \mathrm{M}^{-1}\right) \\
0.6 \mathrm{M} \mathrm{NaCl} \\
1^{\circ} \mathrm{C}\end{array}$ \\
\hline APC-33 & 1 & 2 & 50 & 55 & $7.0 \pm 0.5$ & $0.3 \pm 0.2$ \\
\hline $\mathrm{M} 1 \cdot \mathrm{M} 2$ & 1 & 2 & 47 & & & \\
\hline ps-N1 & 1 & 2 & 39 & 50 & $1.0 \pm 0.1$ & $1.0 \pm 0.1$ \\
\hline ps-C4 & 2 & 1 & 49 & & & \\
\hline aps AT & 2 & 1 & 67 & 82 & $>100$ & $>100$ \\
\hline $\mathrm{M} 1 \cdot \mathrm{M} 3$ & 1 & $1^{\S}$ & 45 & & & \\
\hline
\end{tabular}

*For comparison the CD signals for DstA binding to the different oligonucleotides were

calculated per bound DstA molecule rather than per nucleotide (as in the figures with CD spectra).

$\ddagger K_{\text {lass }}$ for the first and $K_{2 a s s}$ for the second DstA molecule were estimated by fitting the experimental titration curves (Figure 8A,B,C); see text.

\$For monomeric binding of Dst into a groove.

The different affinities of the first and second DstA molecules binding to APC-33 may reflect non-equivalent binding potentials of the grooves of the ps [5'$\mathrm{d}$ (AAATT)-3'] [5'-d(TTTAA)-3'] fragment, as sugggested below in the molecular modelling section in which we present a hydrogen bonding scheme for the complex ps [5'-d(AAATT)-3'] [5'-d(TTTAA)-3']:2DstA.

Our data are consistent with the previous observations $(33,34)$ that the affinities of groove-binding ligands to ps sites are much lower than to specific 4-5 bp aps sites. It should be emphasized that in the case of APC-DNA, the ps-N1 hairpin, or the M1-M2 duplex, no perfect 4-5 bp aps binding site can be formed by alternative structures with mismatches, such as the hp-33 (Figure 2) or similar mismatched duplexes of M1 and M2.

Structures of Duplexes $M I \cdot M 3, M 1 \cdot M 2$ and Their Complexes with DstA Revealed by Chemical Probes

According to Wemmer et al. (23), three A.T base pairs are not sufficient for binding DstA. However, the structure proposed as an alternative to APC is irregular with two bulges (Figure 2B), and one cannot dismiss the ad hoc possibility of a preferential, stabilizing interaction with DstA. Thus, we devised experiments based on chemical modification to probe further for distinguishing conformational features. Since the segment of supposedly ps-DNA in the complex of DstA with M1·M2 consisted of A.T base pairs, we resorted to the use of pyridine-OsO $\mathrm{O}_{4}$, a reagent known to modify accessible thymines (35). The results of such modification experiments with the ${ }^{32} \mathrm{P}$-labeled M1 strand in the duplexes M1.M3 and M1·M2 as well as the complex of M1.M2 with DstA are given in Figure 9. It is evident that in the free single-stranded M1 two thymines of the central part were well exposed to pyridine-OsO $\mathrm{O}_{4}$ (Figure 9D), whereas their reactivity within the duplex M1.M2 was 


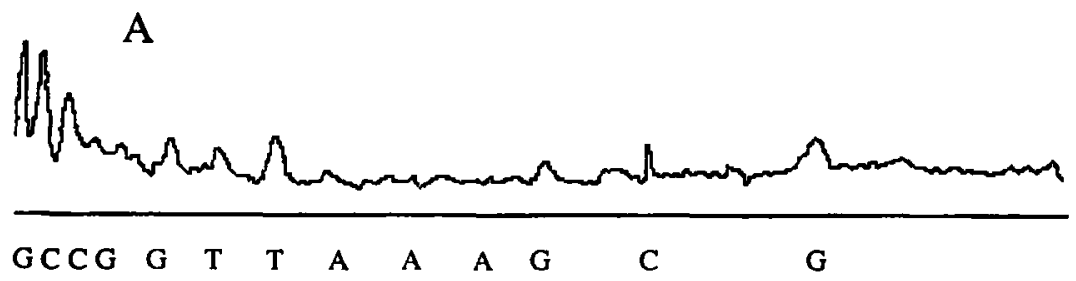

\section{Shchyolkina et al.}

Figure 9: Chemical modification by pyridine-O $\mathrm{OS}_{4}$ of thymines in the $\mathrm{Ml}$ strand incorporated into MI-M3 and M1·M2. (A) free M1-M3; (B) M1.M2 + saturating DstA; (C) free M1.M2; (D) single-stranded Ml control.
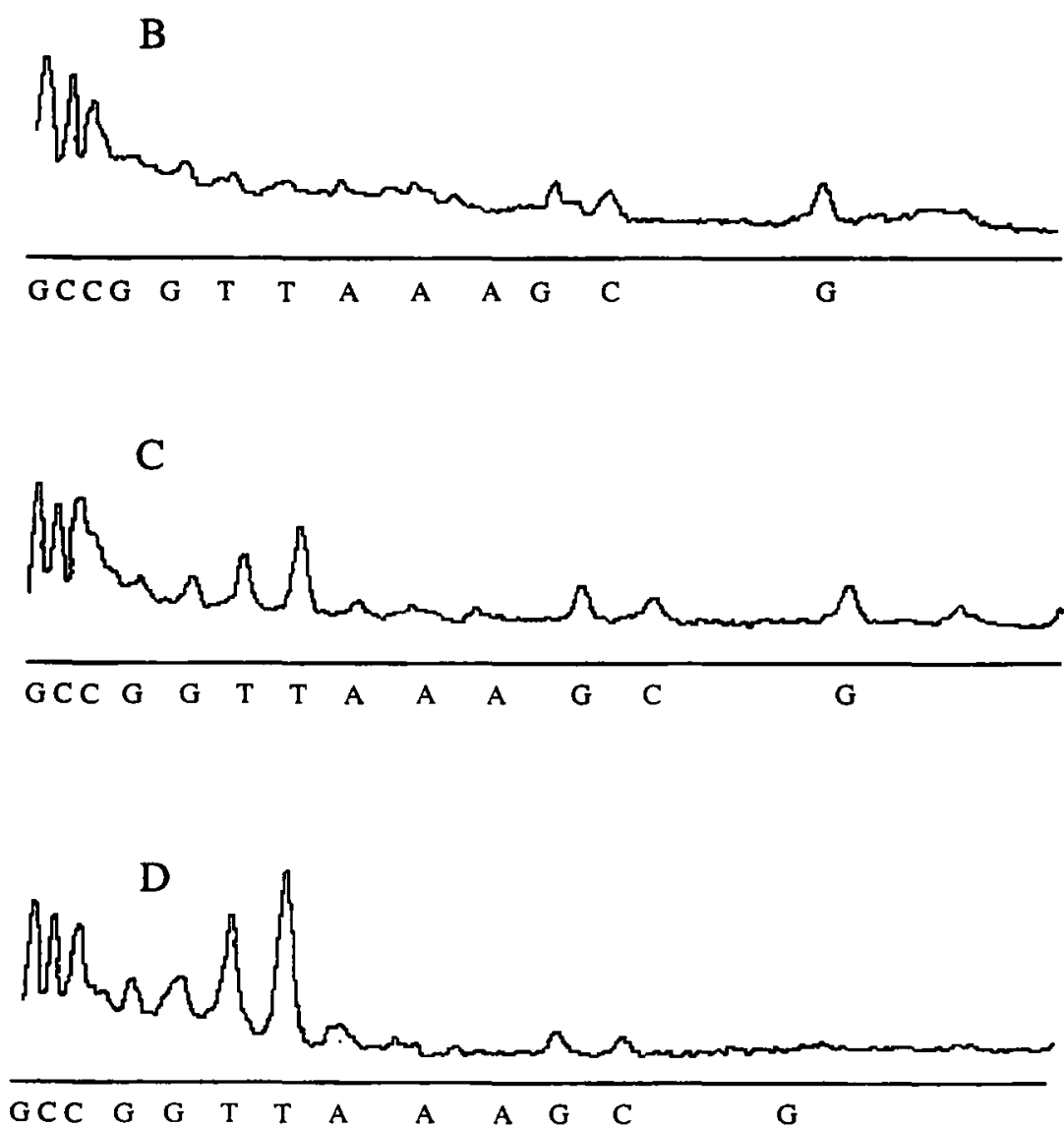

reduced to approximately half (Figure $9 \mathrm{C}$ ). Furthermore, in the presence of saturating concentrations of DstA, these thymines were practically unmodified. The same was true for the perfect aps duplex M1·M3 (Figures 9A,B). In other experiments (data not shown), we determined that $S 1$ nuclease was much less active in the hydrolysis of the thymine-containing segment in the complex of M1-M2-DstA compared to the free duplex.

It should be noted that another structure lacking a ps segment fragment but presenting four bulged bases is possible for M1-M2 (Figure 2B). However, we infer from Figure 9 that this structure does not arise, at least in the presence of DstA.

Thermal Stability of the APC:DstA and MIM2:DstA Complexes

The thermal denaturation of the $2: 1$ complexes of DstA with M1.M2 and APC-33 were analyzed in terms of the respective two-state models for duplex or hairpin molecules. Such an analysis assumes that the melting is concerted, i.e., that drug dissociation occurs concomitantly with the helix-coil transition and that rebinding of the liberated dye can be neglected. The presence of significant fractional concentrations of intermediate species is reflected in an all-or-none analysis by a broadening of the transition (lower apparent $\Delta H$ ). DstA strongly stabilized the structures of $\mathrm{M} 1 \cdot \mathrm{M} 2$ and APC-33 and rendered the transitions more cooperative (Figures 10A,B); the two state analyses invariably provided good fits to the data. In 
the case of $\mathrm{M} 1 \cdot \mathrm{M} 2$, each DstA contributed $5-6^{\circ}$ to the $T_{\mathrm{m}}$ and $\sim 45 \mathrm{~kJ} \mathrm{~mol}^{-1}$ to the apparent $\Delta H$. The corresponding values for APC-33 were approximately half. The increased cooperativity induced by DstA may be associated primarily with the low temperature component of the melting curve dominated by A.T base pairs. The latter are selectively stabilized by the ligand (DstA). Thus, the entire molecule melts more in accordance with the all-or-none model, probably due to a decrease in the initiation parameter that poises the transition at a higher value of the mean base pair stability constant (27).

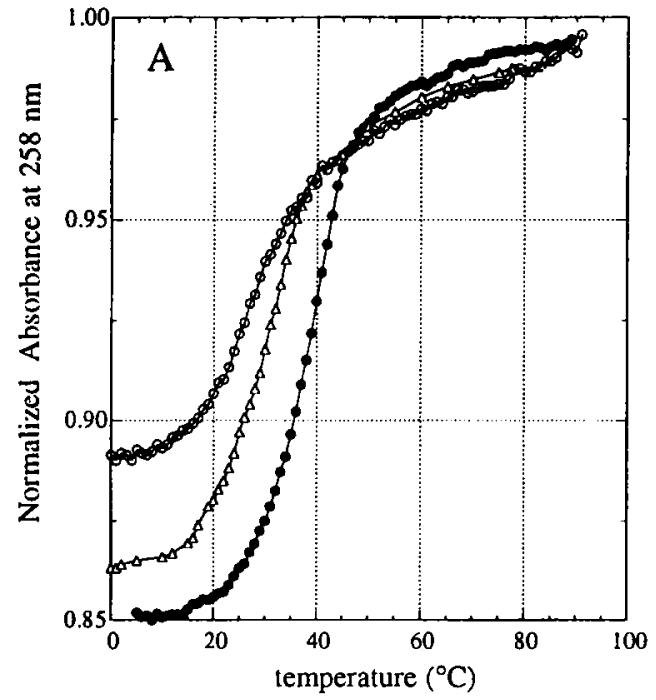

Molecular Model of the APC:2Dst Complex

The junctions of the ps-aps segments of the APC DNA molecule (Figure 1) form large "holes" so as to accommodate a DstA molecule in the grooves of the central psDNA region. The APC DNA and distamycin complexes were modeled by docking two DstA molecules into the grooves of the central d(AATTT) ps stretch using the DOCK command of the SYBYL 6.2 (Tripos) molecular modeling package. The docking was performed in order to optimize the van der Waals contacts and the hydrogen bonding of the DstA drugs. Due to the asymmetry of a DstA molecule, there are four different distinct possibilities for orienting the two drugs in the grooves of the ps-DNA motif. The fully charged DNA-DstA complex was minimized with the AMBER V4.1 package to an rms of 0.01 (36). The total internal energies of the four DNA-drug orientations did not differ appreciably after minimization.

Stereo models for the DstA-APC complex are presented in Figures 11 and 12. We note a unique feature of the $5^{\prime}$-(TTTAA)-3' groove, i.e. the presence of a "mini-groove" formed by the thymine methyl groups and the sugar phosphate backbone (Figure 11). This "mini-groove" is just wide enough to accommodate one DstA molecule, resulting in a tighter binding than in the other groove. During the minimization, the structures of APC and the distamycin drug in the $5^{\prime}$ (AAATT)-3' groove did not change significantly, whereas the distamycin in the $5^{\prime}$ (TTTAA)-3' groove adjusted its geometry in order to fit into the "mini-groove". Combined with the distinctive hydrogen bonding patterns (see below), this observation provide a rationale for the different affinities of the first and second DstA molecules obtained bound at high salt concentration; i.e., the binding potentials of the two grooves in the proposed APC structure differ inherently.

Inspection of the hydrogen bonding schemes in the minimized structures revealed that the DstA molecule associated with the $5^{\prime}$-(TTTAA)-3' groove of the ps stretch formed four hydrogen bonds as opposed to three for the DstA in the other groove (Figure 12). In addition to the expected involvement of the N3 atoms of adenine and carbonyl groups of thymine in hydrogen bonding to DstA, an N7 atom of the second
Distamycin-stabilized Antiparrallel-Parrallel Combination (APC) DNA

\section{Combination (APC) DNA}


adenine in the $5^{\prime}$-(AATTT)-3' segment was hydrogen bonded to an amide group of one drug molecule, a novel feature not observed in complexes with B-DNA.

\section{Shchyolkina et al.}

\section{Concluding Remarks}

The combined structure previously designated as Antiparallel-Parallel-Combination DNA (APC-DNA) (11) was characterized experimentally in this report by CD and absorption spectroscopy and by chemical modification. We consider that the set of interrelated experiments on the APC oligonucleotide and control hairpins provide the neccessary primary and supporting data for the following conclusions. (i) In conventional aps-DNA, an internal $5^{\prime}$-d(AAATT)-3' $/ 5^{\prime}$-d(TTTAA)- $3^{\prime}$ mismatched (in the aps sense) region can adopt a novel fully base paired conformation consisting of a half turn of a ps double helix. (ii) The groove-binding ligand DstA stabilizes the ps segment by binding to its two similar grooves. While we cannot (and do not) claim that the proposed molecular models are unique or even preferred, they are in good accord with the experimental results and provide a basis for experimental strategies directed at further studies of APC-like molecules.

We thank Ms. Gudrun Heim for excellent technical assistance, Dr. D. Pörschke for help with some of the UV melting experiments, Dr. V. Kuryavyi for help in generating Figure 1, and Drs. A. S. Zasedatelev and R. M. Clegg for helpful discussions. This study was partially supported by the Russian Foundation for Fundamental Research and by the Max Planck Society.

\section{References and Footnotes}

1. J. van de Sande, N. B. Ramsing, M. W.Germann, W. Elhorst, B. W.Kalish, E. Kitzing, R. T. Pon, R. C. Clegg and T. M. Jovin, Science. 241, 551-557 (1988)

2. N.B. Ramsing and T.M. Jovin, Nucleic Acids Res. 16, 6659-6676 (1988)

3. N. A. Tchurikov, B. K.Chernov, Yu. B.Golova and Yu. D. Nechipurenko, Dokl. Akad. Nauk SSSR (USSR). $303,1254-1258$ (1988)

4. N. A. Tchurikov, B. K.Chernov, Yu. B.Golova and Yu. D. Nechipurenko, FEBS Lett. 257, 415 418 (1989)

5. A. K. Shchyolkina, Yu. P.Lysov, I. A. Il'icheva, A. A. Chernyi, Yu. B. Golova, B. K. Chemov, B.P. Gottikh and V. L. Florentiev, FEBS Lett. 244, 39-42 (1989)

6. M. W. Germann, H. J. Vogel, R. T. Pon and J. H. Van de Sande, Biochemistry 28, 6220-6228 (1989)

7. V. V. Kuryavyi, Mol. Biol. (Russ.) 21, 1486-1496 (1987)

8. T. M. Jovin, Nucleic Acids Molec. Biol. 5, 25-38 (1991)

9. K. Rippe, V. Kuryavyi, E. Westhof and T.M. Jovin, In: Structural Tools for the Analysis of Protein-Nucleic Acid Complexes. Advances in Life Sciences (ALS). Lilley, D. M., Heumann, H., and Suck, D., editors. Birkhauser Verlag, Switzerland, Basel. 81-107 (1992)

10. N. A. Tchurikov, A. K. Shchyolkina, O. F. Borissova and B. K. Chemov, FEBS Lett. 297, 233. 236 (1992)

11. V. I. Ivanov, N. B. Ulyanov, V. B. Zhurkin and R. H. Sarma, In : Book of Abstracts of Conference "Trends in DNA Structure-Function and Genome Organization". Bangalore, India. p. $16(1993)$

12. M. Z. Gorgoshidze, PhD Thesis (Russ.). Institute of Molecular Biology, Moscow, Russia (1992)

13. C. Zimmer, K.E. Reinert, G. Luck., U. Wahnert, G. Lober, H. Thrum, J. Mol. Biol. 58, 329. 348 (1971)

14. G. Luck, C. Zimmer, K.-E. Reinert and F. Arcamone, Nucleic Acids Res. 4, 2655-2670 (1977)

15. C. Zimmer, G. Luck, E.Birch-Hirshfeld, R. Weiss, F. Arcamone and W. Gushlbauer, Biochim. et Biophys. Acta. 741, 15-22 (1983)

16. X. Chen, B. Ramakrishnan and M. Sundaralingam, J. Mol. Biol. 267, 1157-1170 (1997)

17. S. Neidle, Biopolymers. Nucleic Acid. Sci. 1, 105-121 (1997)

18. N. Pattabiraman, Biopolymers 25, 1603-1606 (1986)

19. N. Zhou, M.W. Germann, J.H. van de Sande, N. Pattabiraman and H.J. Vogel., Biochemistry 32, 646-656 (1993)

20. M. L. Kopka, C.Yoon, D. Goodsell, P. Pjura and R. E. Dickerson, Proc. Natl. Acad. Sci. USA $82,1376-1380(1985)$

21. M. W. Germann, N. Zhou, J. H. van de Sande and H. J. Vogel, Meth. Enyzmol. 261, 207-225 (1995)

22. J. G. Pelton and D. E. Wemmer, Proc. Natl Acad Sci. USA 86, 5723-5727 (1989)

23. D. E. Wemmer, B. H. Geierstanger, P. A. Fagan, T. J. Dwyer, J. P. Jacobsen, J. G. Pelton, G. E. Ball, A. R. Leheny, W.-H. Chang, Y. Bathini, J. W. Lown, D. Rentzeperis, L. A. Marky, S. Singh and P. Kollman, In : Struct. Biology, The State of Art. Proc. of the Eighth Conversation SUNY, NY. Sarma, R. H., and Sarma, M. H., editors. Adenine Press, San Diego. 301-323 (1994) 
24. L. E. Minchenkova, A. K. Shchyolkina, B. K. Chernov and V. I. Ivanov, J. Biomol. Struct. Dynam. 4, 463-475 (1986)

25. K. Rippe, N. B. Ramsing and T. M. Jovin, Biochemistry 28, 9536-9541 (1989)

26. A.F. Melnikova, A.S. Zasedatelev, A.M. Kolchinskii, G.V. Gurskii, A.L. Zhuze,

S.L.Grokhovskii and A.D. Mirzabekov, Molecular Biology Reports 2, 135-142 (1975)

27. E. M. Evertsz, K. Rippe and T. M. Jovin, Nucleic Acids Res. 22, 3293-3303 (1994)

28. M. Z. Gorgoshidze, E. E. Minyat, A. A. Gorin, E. Ya. Demchuk, V. A. Farutin and V. I. Ivanov, Mol. Biol. (Russ.) 26, 1263-1273 (1992)

29. A. M. Maxam and W. Gilbert, Methods Enzymol. 65, 499-559 (1980)

30. M. Coll, C.A. Frederick, A. H.-J. Wang and A. Rich, Proc. Natl. Acad Sci. USA 84, 8385-8389 (1987)

31. S.B.Singh, D.E. Wemmer and P.A. Kollman, Proc. Natl. Acad. Sci. USA 91, 7673-7677 (1994)

32. E.Keller, J. Appl. Crystallogr. 22, 19-21 (1989)

33. H. Fritzsche, A. Akhebat, E. Taillandier, K. Rippe and T. M. Jovin, Nucleic Acids Res. 21 , 5085-5091 (1993)

34. J.van de Sande, B.W. Kalish, M.W. Germann, In: Molecular basis of specificity in nucleic acids-drug intercations. B.Pullman and J.Jortner, editors. The Jerusalem Symposium on Quantum Chemistry and Biochemistry 23, 261-274 (1991)

35. J. Klysik, W. Zacharias, G. Galazka, M.Kwinkowski, B. Uznanski and A. Okruszek, Nucleic Acids Res. 16, 6915-6933 (1988)

36. D.A. Pearlman, D.A. Case, J.W.Caldwell, W.S. Ross, T.E. III Cheatham, D.M. Ferguson, G.L.Seibel, U. Chandra Singh, P.K. Weiner and P.A. Kollman, AMBER 4.1, University of California, San Francisco (1995)

Date Received: January 8, 1998

\section{Communicated by the Editor Ramaswamy H. Sarma}

